\title{
Health risk analysis for the role of dust and gaseous air pollution on bronchitis in children
}

\author{
O. Herbarth ${ }^{1,2}$, G. Fritz ${ }^{2}$, P. Krumbiegel ${ }^{1}$, U. Diez, U. Franck ${ }^{1}$, M. \\ Richter ${ }^{1}$ \\ ${ }^{1}$ Dept. Human Exposure Research and Epidemiology at UFZ, Leipzig, \\ Germany \\ ${ }^{2}$ Environmental Hygiene and Epidemiology, Medical Faculty, \\ University of Leipzig, Leipzig, Germany
}

\section{Abstract}

The general morbidity is being influenced to a great extent by air way diseases. Since their incidence and prevalence have been increasing, the identification of causal factors is of importance for preventive strategies. Primary irritative, gaseous (like sulfur dioxide $\left(\mathrm{SO}_{2}\right)$ ) as well as particulate pollutants (like TSP) can be regarded as causal constituents. Using the opportunity of changing levels of ambient air pollution in East Germany since 1989, the impact of $\mathrm{SO}_{2}$ and TSP on bronchitis was investigated over the last 10 years as part of several intervention studies with children. The data suggest a significant association between $\mathrm{SO}_{2}$ and the prevalence of bronchitis in children but not for TSP. Considering the findings of other studies, these results would amend the hypothesis put forward in a review of the literature as TSP < ultrafine particles $\left(\mathrm{SO}_{4}{ }^{2-}\right) \leq \mathrm{SO}_{2}$. Although these data show a significant association with only $\mathrm{SO}_{2}$, this does not imply that ultrafine particles, such as $\mathrm{SO}_{4}{ }^{2-}$, do not contribute to the association with the observed adverse health effects. Nevertheless, the findings

Adapted from a draft version of "Effect of sulfur dioxide and particulate pollutants on bronchitis in children - a risk analysis" by Olf Herbarth, Gisela Fritz, Peter Krumbiegel, Ulrike Diez, Ulrich Franck, Matthias Richter. Environmental Toxicology, in press. Copyright (c) 2001 John Wiley and Sons, Inc. Used by permission of John Wiley and Sons, Inc. 
suggest that TSP seems less likely to be a predictor in the association with respiratory diseases, particularly not in the presence of high $\mathrm{SO}_{2}$.

\section{Introduction}

The discussion about the role of different types of pollution exposures in influencing specific clinical diseases is at times contradictory. This is especially true in regard to the influence of ambient particulate matter and/or gaseous irritant noxae on airway diseases. This may be explained by the fact that epidemiological studies are carried out in different countries and regions always focusing on the type of exposure predominating in the area under investigation. This way, the study design and maybe also the target variables are comparable, however, the factors of influence may not be. The problem is even worse when the combined effects of two exposures, particulate matter and/or gaseous irritant noxae, are considered. The two substances need not be emitted by the same source. However, if the health impact is to set the standard for preventive measures, the role of each of the two substances in the development of the disease - in this case airway diseases - must be determined. Should the effect of the two pollutants be determined as different but equal in magnitude, eliminating the source(s) of the more serious exposure, namely $\mathrm{SO}_{2}$ or particulate matter, may be necessary in order to reduce disease prevalence and incidence.

$\mathrm{SO}_{2}$ and particulates are among the pollutants which are internationally regulated by law. The WHO recommended limits have by some countries been adopted as national standards. Airway diseases contribute in a major way to the general morbidity. In Germany, about $13 \%$ of all causes of death are attributable to airway diseases (Konietzko et al. [ 22 ]). Approximately $4 \%$ of all Germans suffer from chronic bronchopulmonary diseases (Fischer [ 11 ]). The prevalence of chronic bronchitis is about 5\% among the population under-20 and $30 \%$ among those age 70 and over (Nolte [ 25 ]). Very high incidences and prevalences are particularly found among children, irrespective of their lifestyle and burden, with figures of up to $60 \%$ being recorded in the past among children aged $0-7$ years in Leipzig (Herbarth [ 15 ]). Whether children who suffered frequently from airway diseases in early childhood will in later life be afflicted by chronic airway diseases has not yet been ascertained. Neither are the factors nor the exact circumstances known in detail which affect or trigger such diseases in (early) childhood. Against this background, studies and meta-analyses of studies (and events) were conducted, trying to answer the central question which of the many possible (and measured) exposure factors are of decisive importance in the development of airway diseases. The knowledge gained is necessarily restricted to the respective areas investigated, since analyses have increasingly shown that they are not simply transferable to other regions.

\subsection{Exposures}

The types of exposures which have been found linked to airway diseases include gaseous substances and ambient inhalable particulate matter. Discussion 
repeatedly focuses on TSP (total suspended matter), particulate matter $(<10 \mu \mathrm{m})$ (PM10), acid aerosols and $\mathrm{SO}_{2}$. The link between these chemical compounds and air way diseases is ranked by Lippmann and Thurston [ 23 ] citing Özkaynak and Thurston [ 26 ], Dockery et al. [ 8 ] and Thurston et al. [ 32 ] as follows:
TSP $<$
PM10 <
PM2.5 <
$\mathrm{SO}_{4}{ }^{2-}$

Significant associations have been observed in this order between particulate air pollution and human health effects. Table 1 presents findings of various studies involving children listing the type-of-exposure-dependent health effects (airway diseases and symptoms). Investigations carried out in the 1980s highlighted associations between high levels of pollution and airway diseases. At that time investigations focused particularly on (acute) pollution episodes (smog), whereas in the 1990s work tended to concentrate on the general situation of air hygiene. Table 1 lists only those studies which report exact exposure measurements and health effects. Studies which dealt with changes in airway function parameters without visible symptoms were not included, neither were studies on croup. The nomenclature of the health effects are those used by the authors cited. Although in some instances contradictory, these findings indicate generally the involvement of air pollution in airway diseases, yet, they do not allow to generalize about a special role of $\mathrm{SO}_{2}$ as a representative of the primary irritant components or particulate matter. This also applies for a retrospective metaanalysis of the 1952 London smog episode. Not even a component breakdown into $\mathrm{SO}_{2}$, smog and acidity resulted into a differentiation (Thurston [ 32 ]).

\subsection{Problem statement and hypotheses}

Comparisons of populations, subjected to different levels of air pollution, may be prone to overlook major factors of influence beyond the exposure itself and may also ignore specific peculiarities which exist between populations. Although, the air pollution components may be the same, locally occurring episodes cannot be assumed to be the same in the other area under investigation. Furthermore, the "dosage", i.e. the temporal distribution of the pollutants in terms of type and duration, is of importance. The cited studies (Table 1) generally do lack a detailed description of this.

Thus, results obtained in a certain region are very often generalized to other areas without taking into account the specific peculiarities of that area. This applies particularly to investigations into the role of $\mathrm{SO}_{2}$ and dust in airway diseases. A number of epidemiologic studies have investigated the effects of particles under specifically German and in the broadest sense central European conditions.

It is very difficult to distinguish between health effects due to $\mathrm{SO}_{2}$ or sulfate on airway diseases, because the occurrence of $\mathrm{SO}_{2}$ is followed by nucleation and hence the formation of sulfate particles - very tiny particles which do not greatly contribute to the mass of TSP, PM10 or PM2.5. Therefore, carefully targeted studies are needed if a distinction is to be drawn at least between the effect of $\mathrm{SO}_{2} / \mathrm{SO}_{4}$ and particulate matter (according to TSP, PM10 or PM2.5) on airway diseases. Thus, considering the findings of previous epidemiological studies conducted in this area as a basis, the following hypothesis is being examined in 
this study: (Acute) Bronchitis is - under the specific air-hygiene conditions of the regions under investigation - more closely associated with $\mathrm{SO}_{2}$ than with the mass concentration of TSP. The occurrence of bronchitis was considered with respect to the total lifetime burden of these children.

Table 1: Examples of epidemiological studies associating air pollutants with airway diseases in children

\begin{tabular}{|c|c|c|c|}
\hline \multirow[t]{2}{*}{ Effect observed } & \multicolumn{2}{|c|}{ Pollutant } & \multirow[t]{2}{*}{ Reference } \\
\hline & with effect & no effect & \\
\hline Bronchitis without fever & $\mathrm{SO}_{2}$ & & Bredel [3] \\
\hline Bronchial irritation & $\mathrm{SO}_{2}, \mathrm{SO}_{4}{ }^{2-}$ & & Dodge [9] \\
\hline Respiratory diseases & $\mathrm{SO}_{2}$ deposition & $\mathrm{SO}_{2}, \mathrm{PM}$ & Marty [24] \\
\hline Respiratory health & $\mathrm{SO}_{2}, \mathrm{TSP}$ & & Spinaci [31] \\
\hline Respiratory symptoms & $\mathrm{SO}_{2}$ & & Charpin [4] \\
\hline Acute respiratory effects & $\mathrm{SO}_{2}$ & & David [7] \\
\hline Respiratory diseases & $\mathrm{SO}_{2}$ & $\mathrm{NO}_{2}$ & Agocs [1] \\
\hline Pulmonary function & $\mathrm{SO}_{2}, \mathrm{NO}_{2}, \mathrm{O}_{3}$ & & Schmitzberger [30] \\
\hline Acute respiratory effects & & $\mathrm{SO}_{2}, \mathrm{BS}, \mathrm{PM}$ & Hoek [18] \\
\hline Wheeze & $\mathrm{PM} 10, \mathrm{BS}, \mathrm{SO}_{2}$ & & Roemer [27] \\
\hline Symptoms of bronchitis & $\mathrm{PM}, \mathrm{SO}_{4}{ }^{2-}$ & & Damokosh [6] \\
\hline Asthma attacks & $\mathrm{SO}_{2}$ & & Garcia-Marcos [12] \\
\hline Acute respiratory symptoms & & $\begin{array}{l}\mathrm{O}_{3}, \mathrm{PM10} \\
\mathrm{NO}_{4}, \mathrm{SO}_{4}\end{array}$ & Hoek [19] \\
\hline $\begin{array}{c}\text { Respiratory symptoms } \\
\text { cough } \\
\text { LRS } \\
\end{array}$ & $\begin{array}{l}\mathrm{PM} 10 \\
\mathrm{SO}_{2}, \mathrm{O}_{3} \\
\mathrm{SO}_{2} \\
\end{array}$ & $\begin{array}{l}\text { Aerosol } \\
\text { acidity }\end{array}$ & Schwartz [29] \\
\hline Respiratory illness & NOx & $\begin{array}{l}\mathrm{SO}_{2}, \mathrm{CO}, \mathrm{O}_{3}, \\
\mathrm{BS}\end{array}$ & Keiding [ 21] \\
\hline Bronchitis & $\mathrm{SO}_{2}$ & & Herbarth [14] \\
\hline $\begin{array}{r}\text { Lower respiratory illness } \\
\text { cough }\end{array}$ & $\begin{array}{l}\text { TSP } \\
\mathrm{TSP}, \mathrm{SO}_{2}, \mathrm{TSO}_{4}\end{array}$ & & Ware $[33]$ \\
\hline Bronchitis & $\mathrm{SO} 2$ & & Herbarth [16] \\
\hline Respiratory symptoms & TSP, $\mathrm{SO}_{2}$ & & Jedrychowski [20] \\
\hline Respiratory illness & $\mathrm{SO}_{2}, \mathrm{PM}$ & & Cerna [5] \\
\hline Airway diseases & $\mathrm{SO}_{2}$ & & Herbarth [17] \\
\hline Asthma and LRS & $\mathrm{NO}_{2}, \mathrm{CO}, \mathrm{SO}_{2}$ & PM10 & Hajat $[13]$ \\
\hline
\end{tabular}

Remarks: BS - black smoke, TSP - total suspended matter, $\mathrm{TSO}_{4}$ - total sulphate, LRS - lower respiratory symptoms, PM - particulate matter

\section{Method}

In 1994 and 1998, two cross-sectional studies (KIGA and LISS) investigating the role of different types of pollution exposures in airway diseases were carried out in Leipzig. The KIGA-study (study on airway diseases and allergies among KInderGArten children) and LISS-study (the Leipzig Infection, airway disease and allergy study on School Starters) were complemented by an additional investigation KIGA-IND, based on the KIGA design and focus, and conducted in three differentially polluted industrial areas (the Mansfelder Land, the Bitterfeld 
area and the coal mining area along the southern outskirts of Leipzig). Study subjects were children between 5 and 7 years old. The LISS study was divided in LISS-U for the urban area and in LISS-R for the rural area around Leipzig. The investigation which is presented here is focused on acute bronchitis in young children. The findings presented are based on the analysis of a parent-completed questionnaire, identical in all studies. $93 \%$ of the KIGA study participants were born between 1987 and 1990, while $89 \%$ of the LISS sudy were born in 1991/92, $65 \%$ of the KIGA-IND-study participants between 1990 and 1993. The total lifetime exposure burden corresponds to the exposure duration from the year of birth to the time of the study. The time between 1987 and 1999 is characterised by a dramatical change of exposure. The exposure assessment is based on emission data supplied by the State Department of the Environment and Geology of Saxony as well as the State Department of the Environment of Saxony-Anhalt and the State Institute of Hygiene in Leipzig. The data are based on respective regional monitoring networks and progammes, using only those monitoring stations representative of the relevant areas under investigation. Measurement techniques are described in FAG [ 10] and APSA [2 ].

\section{Results}

The ambient air-pollution situation (yearly arithmetic mean) with respect to $\mathrm{SO}_{2}$, and particulate matter (TSP), are shown in the Figure 1 for KIGA and LISS-U, Figure 2 for LISS-R and Figure 3 for KIGA-IND. Measurement data of both variables cover the period of the lifetime of the children.
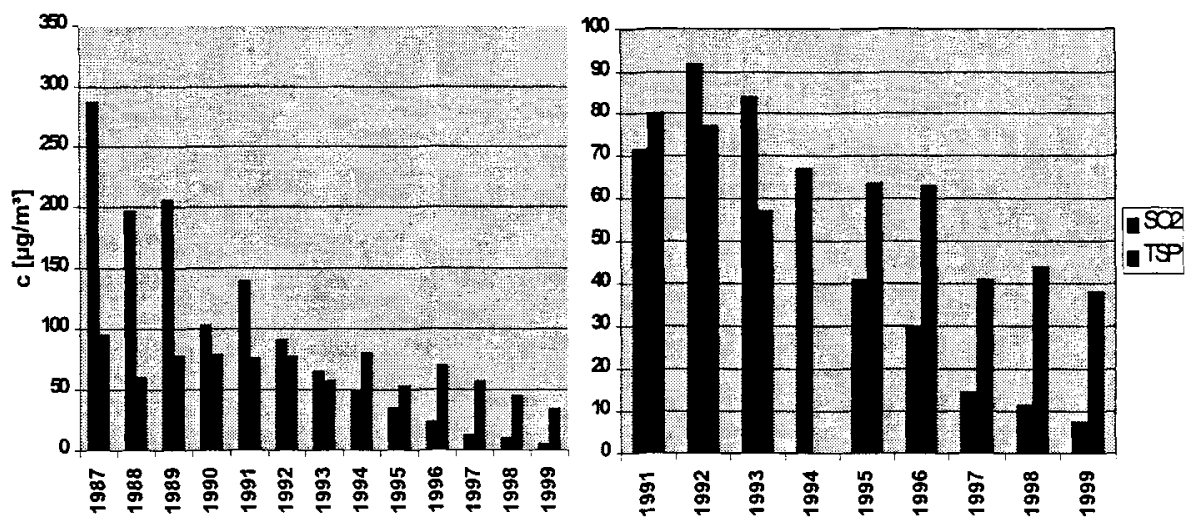

Figure 1 (left) : $\mathrm{SO}_{2}$ and TSP for the urban centre of Leipzig (LISS-U, KIGA) Figure 2 (right): $\mathrm{SO}_{2}$ and TSP for area (LISS-R)

Table 2 depicts the average concentrations of $\mathrm{SO}_{2}$ and particulates, the study participants were exposed to during their lifetime in their area of residence, 
showing clearly the changes and differences in the load of the groups. The highest bronchitis prevalence was found in the KIGA and the lowest in the LISS cohort. This is in accordance with the children's lifetime exposure burden of $\mathrm{SO}_{2}$. The correlative link between sulfur oxide and bronchitis is clearly visible $(R=0.96, p<0.001)$, whereas such an association was not found for TSP in the areas investigated $(R=0.59$, not significant) (Figure 4$)$.

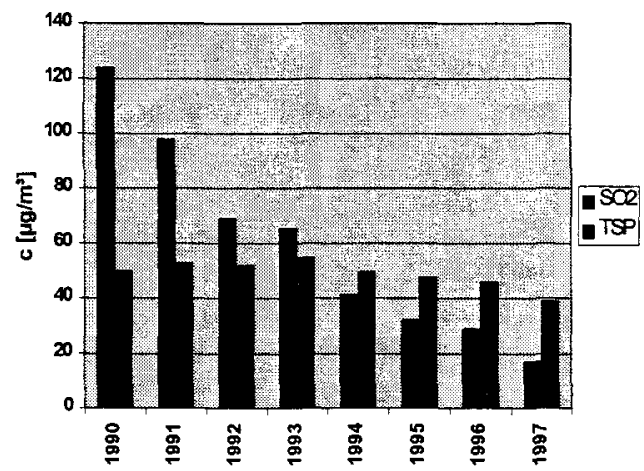

Figure 3: $\mathrm{SO}_{2}$ and TSP of the investigated industrial area (yearly arithmetic mean), representative for KIGA-IND

Table 2: Average lifetime exposure of $\mathrm{SO}_{2}$ and TSP of the study participants determined in the different studies and lifetime prevalences [\%] of bronchitis

\begin{tabular}{|l|c|c|c|}
\hline Study & $\mathrm{SO}_{2}\left[\mu \mathrm{g} / \mathrm{m}^{3}\right]$ & TSP $\left[\mu \mathrm{g} / \mathrm{m}^{3}\right]$ & Bronchitis lifetime prevalence $(95 \% \mathrm{CI})$ \\
\hline KIGA & 142 & 75 & $59.8(54.2-63.3)$ \\
\hline LISS-U & 48 & 61 & $30.8(28.7-32.9)$ \\
\hline LISS-R & 47 & 50 & $32.6(29.7-35.4)$ \\
\hline KIGA-IND & 59 & 49 & $42.4(34.0-50.1)$ \\
\hline
\end{tabular}

A logistic regression has been carried out to assess the odds ratios (OR) for different potential factors of influence. The following table shows the adjusted OR for predisposition (mother or father suffer from bronchitis), environmental tobacco smoking (ETS), smoking during pregnancy or in presence of the pregnant woman and the lifetime exposure for $\mathrm{SO}_{2}$ and TSP.

Table 3: Odds Ratios for bronchitis adjusted for parental predisposition, smoking and exposure against $\mathrm{SO}_{2}$ and TSP

\begin{tabular}{|l|l|c|c|c|}
\cline { 3 - 5 } \multicolumn{2}{c|}{} & $\mathrm{OR}$ & $\mathrm{p}$ & $95 \% \mathrm{CI}$ \\
\hline parental predisposition & 2.18 & $<.0000$ & $1.69 \ldots 2.82$ \\
\hline \multirow{3}{*}{ smoking } & ETS & 0.85 & .034 & $0.73 \ldots 0.99$ \\
\cline { 2 - 5 } & during pregnancy & 0.85 & .074 & $0.67 \ldots 1.08$ \\
\cline { 2 - 5 } & in presence of pregnant woman & 1.19 & .029 & $1.03 \ldots 1.95$ \\
\hline \multirow{2}{*}{$\begin{array}{l}\text { children } \\
\text { exposure }\end{array}$} & $\mathrm{SO}_{2}$ & 3.51 & $<.0000$ & $2.56 \ldots 4.82$ \\
\cline { 2 - 5 } & $\mathrm{TSP}$ & 0.72 & .081 & $0.49 \ldots 1.04$ \\
\hline
\end{tabular}




\section{Conclusions}

Assessed for different parameters, the KIGA study results showed a $50 \%$ increased risk of bronchitis with exposure to typical domestic-heating-associated emission (Herbarth [ 16 ]). Measurements did show that sulfur dioxide was the major component of domestic heating emissions. Particulate matter from domestic heating took largely the form of large, health-irrelevant particulates (sedimentation particulate). These results confirm findings of a previous study conducted in Leipzig of the same type as the LISS and KIGA studies. This study found a clear association between $\mathrm{SO}_{2}$ and the occurrence of bronchitis (without fever) in infants 3 years and younger (Bredel et al. [ 3 ]). In addition, an increased frequency of calls to the mobile emergency medical services due to airway diseases was found associated with $\mathrm{SO}_{2}$, also in Leipzig (Herbarth [ 14 ]). However TSP was not found to be a significant factor. This does not preclude the possibility that the ultrafine fraction of particulate matter may contribute to exacerbations of the effects of $\mathrm{SO}_{2}$ or may be an important risk factor in itself.
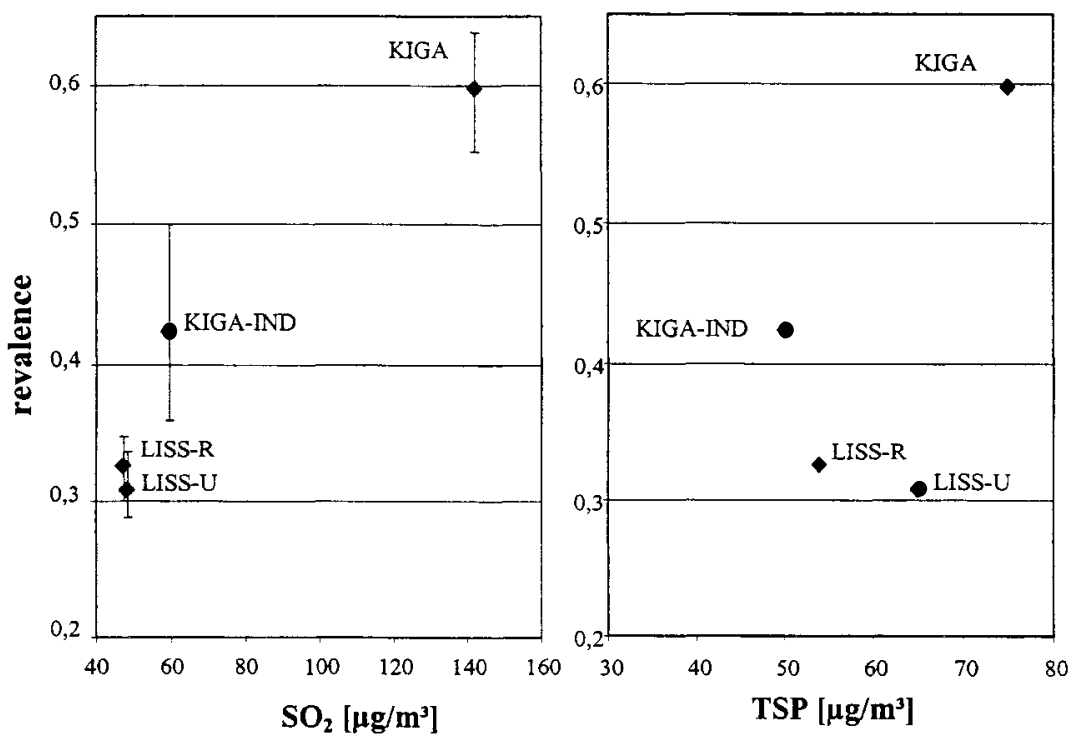

Figure 4: Lifetime prevalences of bronchitis [ $\% / 100]$ vs. sulfur-dioxide exposure and TSP exposure

Although a relationship does exist between $\mathrm{SO}_{2}$ and TSP, it could not be demonstrated for TSP and bronchitis. From these studies it can therefore be concluded that, in these study areas, $\mathrm{SO}_{2}$ was a more important factor than TSP in the occurrence of bronchitis.

These results suggest that $\mathrm{SO}_{2}$ would be a more reliable measure of risk than TSP. As $\mathrm{SO}_{2}$ is also closely associated with sulfate and the latter is counted in 
the ultrafine fraction of particulate matter, it cannot be ruled out that both $\mathrm{SO}_{2}$ and sulfate, contribute to the observed effects. Yet it is difficult to distinguish between their individual actions. The mass concentration of the ultrafine particle fraction of TSP is rather low. As already mentioned, our findings do not preclude the possibility that the ultrafine fraction may contribute to exacerbations of the $\mathrm{SO}_{2}$ effects or may be an important risk factor in itself.

Thus, the association put forward by Lipmann and Thurston [ 23 ]:

TSP $<\mathrm{PM} 10<\mathrm{PM} 2.5<\mathrm{SO}_{4}{ }^{2-}$ may with respect to the influence of $\mathrm{SO}_{2}$ and TSP on airway diseases among children be expressed as follows:

TSP <(ultra)fine particles $\left(\mathrm{SO}_{4}{ }^{2-}\right) \leq \quad \mathrm{SO}_{2}$

Further analyses are required to address questions concerning the modulating (and predisposing) effect of extreme concentration levels (as occurring during smog episodes) and the synergistic effects of $\mathrm{SO}_{2}$ and particulates. Such situations have been registered less and less over the past few years in the study areas.

These findings demonstrate that the dominating influence on bronchitis derived from exposure to sulfur dioxide. Figure 1 to Figure 3 show, $\mathrm{SO}_{2}$ exposure has dramatically decreased over the years, much more so than TSP. If the prevalences of bronchitis in the different areas are correlated with the children's respective lifetime exposures to $\mathrm{SO}_{2}$ and $\mathrm{TSP}, \mathrm{SO}_{2}$ was clearly the more dominant risk factor in the past (Figure 4).

Due to the strong decrease of $\mathrm{SO}_{2}$ over the past of 10 years a level is reached from which we have to expect that these exposures at present do not have a dominant effect on bronchitis. Maybe a chronic exposure together with other components like VOC and small particles (lower than PM 2.5) is able to influence irritations and so bronchitis. For that reason further investigations are necessary to clear up the role of different noxious agents separately and in combination.

\section{References}

[ 1 ] Agocs, M.M.; Rudnai, P.; Etzel, R.A. (1992) Respiratory disease surveillance in Hungary. Mortal Wkly Rep CDC Surveill Summ 41 (4):1-8

[2] APSA (1993) Bedienungsanleitung Horiba APSA-350E, Horiba Europe $\mathrm{GmbH}, 13-14$

[ 3 ] Bredel, H.; Herbarth, O.; Winterstein, P. (1980). Epidemiological study about air pollution and bronchitis in $0.5-3$ years old children. Dt. Gesundh.-Wesen 35 (1): 16 - 18

[4] Charpin, D.; Kleisbauer, J.P.; Fondarai, J.; Graland, B.; Viala, A.; Gouezo, F. (1988). Respiratory symptoms and air pollution changes in children: the Gardanne Coal-Basin study. Arch Environ Health 43 (1): 22-27

[ 5 ] Cerna, M.; Jelinek, R.; Janoutova, J.; Kotesovec, F.; Benes, I.; Leixner, M. (1998). Risk assessment of the common air pollutants in Teplice, Czech republic. Toxicol Lett 96: 203-208 
[6] Damokosh, A.I.; Spengler, J.D.; Dockery, D.W.; Ware, J.H.; Speizer, F.E. (1993). Effects of acidic particles on respiratory symptoms in 7 U.S Communities. Am. Rev. Resp. Dis. 147 (4): A632

[ 7 ] David, A.; Kegel, E.; Rudnai, P.; Sarkany, S.; Kertesz, M. (1990). Studies on correlation between air pollution and respiratory morbidity among children in Dorog. Orvosi Hetilap 131, 513-517

[ 8 ] Dockery, D.W.; Pope, C.A., III; Xu, X.; Spengler, J.D.; Ware, J.H.; Fay, M.E.; Ferris, B.G., jr; Speizer, F.E. (1993). An association between air pollution and mortality in six U.S. cities. N. Engl. J. Med. 329: 1753-1759

[9] Dodge, R.; Solomon, P.; Moyers, J.; Hayes, C. (1985). A longitudinal study of children exposed to sulfur oxides. Am. J Epidemiol 121 (5):720736

[10] FAG (1992) Staubmeßgerät FH62I-N, Bedienungsanleitung, FAG Kugelfischer Georg Schäfer KG, 3-1 - 3-2

[11] Fischer, H.; Eckenberger, H.-P.; van Aubel, A.; Kämmereit, A.; Elsässer, U. (1992) Prävention von Infektrezidiven der oberen und unteren Luftwege. Atemwegs- und Lungenkrankheiten 18 (4): 146-155

[12] Garcia-Marcos, L.; Guillen Perez, J.J.; Niguez, J.C.; Guillen Marco, A. (1993). Air pollution and respiratory disease in children. Experience in Cartagena. An Esp Pediatr 39, Suppl 55: 83-85

[13 ] Hajat, S.; Haines, A.; Goubet, S.A.; Atkinson, R.W.; Anderson, H.R. (1999) Association of air pollution with daily GP consultations for asthma and other lower respiratory conditions in London. Thorax 54 (7): 597-605

[14] Herbarth, O. (1995). Risk Assessment of Environmentally Influenced Airway Diseases Based on Time-Series Analysis. Environ Health Perspect 103 (9): 852-856.

[15] Herbarth O.; Fritz G.J.; Wildführ W.; Behler C. (1997) Microscaled intracity epidemiologic risk analysis of traffic- and domestic-heating-attributed immission effects on airway diseases and allergies among children. Air Pollution 5: 1023-1032

[16] Herbarth, O. (1997) Threshold Values for Environmentally Influenced Diseases Resulting from Time-series Analysis. Epidemiology 8 (4) 61

[17] Herbarth, O.; Fritz, G.J.; Behler, J.C.; Rehwagen, M.; Puliafito, J.L.; Richter, M.; Schlink, U.; Sernaglia, J,; Puliafito, E.; Puliafito, C.; Schilde, M.; Wildführ, W. (1999) Epidemiologic Risk Analysis of Environmentally Attributed Exposure on Airway Diseases and Allergies in Children. Centr. eur. J. publ. Health 7 (2): 72-76

[18 ] Hoek, G.; Brunekreef, B. (1993). Acute effects of a winter air pollution episode on pulmonary function and respiratory symptoms of children. Arch Environ Health 48 (5): 328-335

[19] Hoek, G.; Brunekref, B. (1995). Effect of photochemical air pollution on acute respiratory symptoms in children. Am J Respir Crit Care Med 151 (1): $27-32$

[20] Jedrychowski, W.; Flak, E.; Mroz, E. (1998) Effect of poor air quality on the health of Krakow children. Jagiellonian University, Collegium Medicum. Krakow (ISBN 83-904896-0-1) Chapter 6 
[21 ] Keiding, L.M.; Rindel, A.K.; Kronborg, D. (1995). Respiratory illnesses in children and air pollution in Copenhagen. Arch Environ Health 50 (3): 200-206

[22 ] Konietzko, N.; Wendel, H.; Wiesner, B. (Ed.) (1995) Erkrankungen der Lunge. Walter de Gruyter, Berlin

[23 ] Lippmann, M.; Thurston, G.D. (1996) Sulfate concentrations as an indicator of ambient particulate matter air pollution for health risk evaluations. Journal of Exposure Analysis and Environmental Epidemiology 6(2): 123-146

[ 24 ] Marty, H.; Kümmerli, H.; Zurbrugg, R.P.; Berlincourt, P.; Fillinger, P.; Rickli, R.; Rickli, B.; Wanner, H. (1985). Effect of meteorologic and air hygiene factors on acute respiratory tract diseases in children-based on the example of the Biel region. Schweiz Med Wochenschr 115 (52): 1890-99

[25] Nolte, D. (1991). Asthma: Das Krankheitsbild. Der Asthmapatient. Die Therapie. Urban \& Schwarzenberg, München.

[26] Özkaynak, H.; Thurston, G.D. (1987) Association between 1980 U.S. mortality rates alternative measures of airborne particle concentration. Risk Anal. 7: 449-461

[ 27 ] Roemer, W.; Hoek, G.; Brunekref, B. (1993). Effect of ambient winter air pollution on respiratory health of children with chronic respiratory symptoms. Am Rev Respir Dis 147 (1): 118-124

[28 ] Schwartz, J. (1996) Air pollution and hospital admissions for respiratory disease. Epidemiology 7 (1): 20-28

[29] Schwartz, J.; Dockery, D.W.; Neas, L.M.; Wypij, J.H.; Spengler, J.D.; Koutrakis, P.; Speizer, F.E.; Ferris, B.G.jr. (1994) Acute effects of summer air pollution on respiratory symptom reporting in children. $\mathrm{Am} \mathrm{J}$ Respir Crit Care Med 150 (5): 1234-1242

[ 30 ] Schmitzberger, R.; Rhomberg, K.; Buchele, H.; Puchegger, R.; Schmitzberger-Natzmer, D.; Kemmler, G.; Panosch, B. (1993). Effects of air pollution on respiratory tract of children. Pediatr Pulmonol 15(2):68-74

[ 31 ] Spinaci, S.; Arossa, W.; Bugiani, M.; Natale, P.; Bucca, C.; de Candussio, G. (1985). The effects of air pollution on the respiratory health of children: a cross-sectional study. Pediatr Pulmonol 1(5): 262-266

[ 32 ] Thurston, G.D.; Ito, K.; Hayes, C.G.; Bates, D.V.; Lippmann, M. (1994). Respiratory hospital admissions and summertime haze air pollution in Toronto, Ontario: Consideration of the role of acid aerosols. Environ. Res. 65: 271-290

[33 ] Ware, J.H.; Ferris, B.G. jr, Dockery, D.W.; Spengler, J.D.; Sram, D.O.; Speizer, F.E. (1986). Effects of ambient sulfur oxides and suspended particles on respiratory health of preadolescent children. Am Rev Respir Dis 133 (5): 834-842 